\title{
A Contribuição da Geodiversidade na prestação dos Serviços Ecossistêmicos do manguezal
}

\author{
The Contribution of Geodiversity to the provision of Mangrove Ecosystem Services
}

\author{
RABELO $^{1}$, T. O.; SANTOS $^{2}$, N. M; $\operatorname{COSTA}^{3}$, D. F.S.; NASCIMENTO ${ }^{4}$, M. A. L.; LIMA ${ }^{5}$,Z. M.C. \\ thiarageo@hotmail.com;
}

Resumo

Os Serviços Ecossistêmicos (SE) são bens tangíveis e intangíveis produzidos pelos ecossistemas, utilizados pela sociedade em busca do bem estar humano. Porém, mais recentemente tem se considerado a diversidade das características abióticas de uma paisagem para fins de conservação, ou seja, considerando a geodiversidade local e sua contribuição para a prestação destes serviços. O ecossistema manguezal caracteriza-se como uma área de elevada importância ecológica. Neste ambiente ocorrem áreas de intensos processos biológicos e geoquímicos, além de representar fonte de alimento e renda para populações ribeirinhas. Contudo, para que seja possível essa intensa produtividade, o manguezal depende do aporte de sedimentos fluviais e marinhos, oscilações da maré, redução da energia de ondas, relevo plano e etc. Considerando estes pressupostos, o objetivo deste trabalho foi analisar a importância de compreender a relação entre Geodiversidade e Serviços Ecossistêmicos, enfatizando a influência dos recursos abióticos na dinâmica de prestação dos serviços por este ecossistema.

\begin{abstract}
Ecosystem Services (SE) are tangible and intangible goods produced by ecosystems, used by society in search of human well-being. However, more recently the diversity of the abiotic characteristics of a landscape for conservation purposes has been considered, that is, considering the local geodiversity and its contribution to the provision of these services. The mangrove ecosystem is characterized as an area of high ecological importance. In this environment there are areas of intense biological and geochemical processes, besides being a source of food and income for riverine populations. However, for this intense productivity to be possible, the mangrove depends on the contribution of fluvial and marine sediments, tidal oscillations, wave energy reduction, flat relief and so on. Considering these assumptions, the objective of this work was to analyze the importance of understanding the relationship between Geodiversity and Ecosystem Services, emphasizing the influence of abiotic resources on the dynamics of service delivery by this ecosystem.
\end{abstract}

Palavras-chave: Serviços $\quad$ Ecossistêmicos; Geodiversidade; Manguezal.
Keywords: Ecosystem Services; Geodiversity;
Mangrove.

\section{INTRODUÇÃO}

A discussão sobre os serviços ecossistêmicos (SE) tornou-se relevante no contexto mundial após a sua integração pela Avaliação Ecossistêmica do Milênio (MEA, 2005), antes disto alguns autores já abordavam esta temática, considerando o seu valor e sua importância social, econômica e

${ }^{I}$ Thiara Oliveira Rabelo, Programa de Pós-Graduação em Geografia, Universidade Federal do Rio Grande do Norte, Natal-RN, Brasil

${ }^{2}$ Nayara Marques Santos, Programa de Pós-Graduação em Geografia, Universidade Federal do Rio Grande do Norte, Natal-RN, Brasil 
ambiental, como por exemplo Constanza (1997), Daily (1997), Limburg e Folke (1999) e De Groot (2002). Desde então surgiram várias propostas de classificação para os SE (MEA, 2005; TEEB, 2008; CICES, 2010), que em sua maioria englobam 04 grandes grupos: os serviços de suporte, de regulação, de provisão e culturais.

Os SE são bens tangíveis e intangíveis produzidos pelos ecossistemas, utilizados pela sociedade em busca do bem-estar humano, a exemplo da provisão de alimentos, água potável, atividades de lazer, proteção a desastres naturais, regulação climática, entre outros (CONSTANZA et al., 1997).

Porém, mais recentemente tem se considerado a diversidade das características abióticas do ambiente para fins de conservação, ou seja, considerando a geodiversidade local e sua contribuição para a prestação destes serviços (GRAY, 2011; GRAY, 2013; GRAY; GORDON; BROWN, 2013; HJORT et al., 2015).

Em 2013, quando Gray, Gordon e Brown definiram os serviços abióticos do ecossistema, começou-se a despertar sobre a importante relação entre os recursos bióticos e abióticos, relação esta que segundo Pereira (2012) ainda é pouco feita nas pesquisas e ações de planejamento e gestão do ambiente, principalmente em áreas consideradas como Unidades de Conservação (UCs) ou Áreas de Preservação Permanente (APPs), como por exemplo os manguezais.

O Ecossistema manguezal caracteriza-se como uma das áreas de elevada importância ecológica (SCOTT; JONES, 1995; JUNK et al., 2014). Neste ambiente ocorrem intensos processos biológicos e geoquímicos, além de representar fonte de alimento e renda para populações ribeirinhas. Contudo, para que seja possível essa intensa produtividade, o manguezal depende do aporte de sedimentos fluviais e marinhos, oscilações da maré, redução da energia de ondas, relevo plano, elementos relacionados diretamente à natureza abiótica (LACERDA, 2001).

A importância ambiental, social e econômica dos ecossistemas é reforçada pela identificação da gama de funções e serviços prestados por eles para a sociedade, sendo necessário relacionar as funções ecossistêmicas a, por exemplo, elementos abióticos e tentar compreender a sua contribuição para os serviços prestados pelo ecossistema.

Levando isto em consideração, este trabalho teve por objetivo analisar a importância de compreender a relação entre Geodiversidade e Serviços Ecossistêmicos, enfatizando a influência dos recursos abióticos na dinâmica de prestação dos serviços por este ecossistema. Espera-se que 
esta análise venha a contribuir para futuras pesquisas que pretendam relacionar a contribuição dos elementos abióticos na prestação de serviços ecossistêmicos em áreas de manguezais.

\section{METODOLOGIA}

O presente artigo teve como principal procedimento metodológico a realização de uma revisão e análise bibliográfica de trabalhos que abordam os temas: geodiversidade, manguezal e serviços ecossistêmicos. Como elemento métrico desta revisão buscou-se realizar a obtenção de informações em livros e periódicos indexados, associando-se as palavras-chave com base nos temas acima descritos. Com o propósito de compreender a influência dos elementos abióticos na prestação dos serviços do manguezal, esta relação foi realizada tendo como parâmetro a Common International Classification of Ecosystem Services - CICES (HAINES-YOUNG; POTSCHIN, 2013), que classifica os serviços prestados pelos ecossistemas em serviços de Provisão, Regulação e Culturais.

Considerando isto, foi feita uma relação por meio das informações levantadas na bibliografia sobre a classificação de serviços ecossistêmicos em áreas de manguezais e atividades de campo realizadas em áreas de manguezais na Ilha do Maranhão, relacionando as características abióticas destes ambientes, segundo as observações de Gray, Gordon e Brown (2013) e sua contribuição para a prestação de serviços do ecossistema manguezal.

A partir disto, foi elaborado um quadro síntese onde foi feita a relação de elementos da Geodiversidade como: geologia, relevo, clima e oceanografia e hidrologia, suas atuações nas áreas de manguezais e suas influências aos serviços ecossistêmicos prestados por estas áreas. 


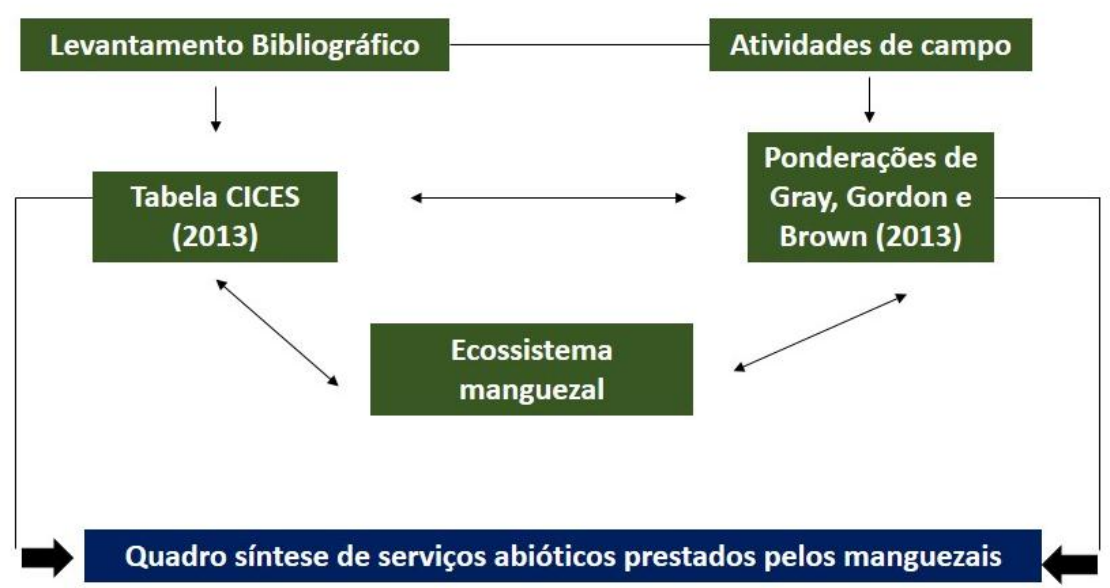

Quadro síntese de serviços abióticos prestados pelos manguezais
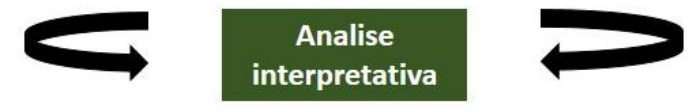

Figura 01: Fluxograma com as principais etapas metodológicas da pesquisa. Fonte: Elaborado pelos autores.

Este quadro foi elaborado com base nos parâmetros encontrados na tabela CICES, que não inclui materiais abióticos e a partir das ponderações de Gray, Gordon e Brown (2013), sendo construída com base nas características do ecossistema trabalhado.

\section{RESULTADOS E DISCUSSÃO}

\subsection{Os Serviços abióticos prestados pela Geodiversidade}

Segundo autores como Gray (2004) e Brilha (2005) a Geodiversidade corresponde a variedade de ambientes geológicos, fenômenos e processos ativos geradores de paisagens, rochas, minerais, fósseis e outros depósitos superficiais que constituem a base para a vida na Terra.

No que corresponde a importância da Geodiversidade para o ser humano e para os demais seres vivos e elementos do ambiente, Nascimento et al., (2008) afirmam que o ato de preservar e conservar está diretamente relacionado a atribuição de algum valor. Desta forma, para pensar em preservação e conservação da Geodiversidade é necessário refletir quais os valores ou serviços que os elementos abióticos prestam para o ser humano e o meio ambiente.

Foi pensando nisto que em 2004, o geógrafo inglês Murray Gray, apresentou em sua publicação “Geodiversity” os valores da Geodiversidade, sendo estes classificados em: intrínseco, cultural, estético, econômico, funcional, científico e educativo. Estes setes valores foram vinculados a 32 subvalores, demostrados por Silva (2016) na figura 01, onde é possível perceber de forma mais detalhada e integrada a relação entre esses valores. 


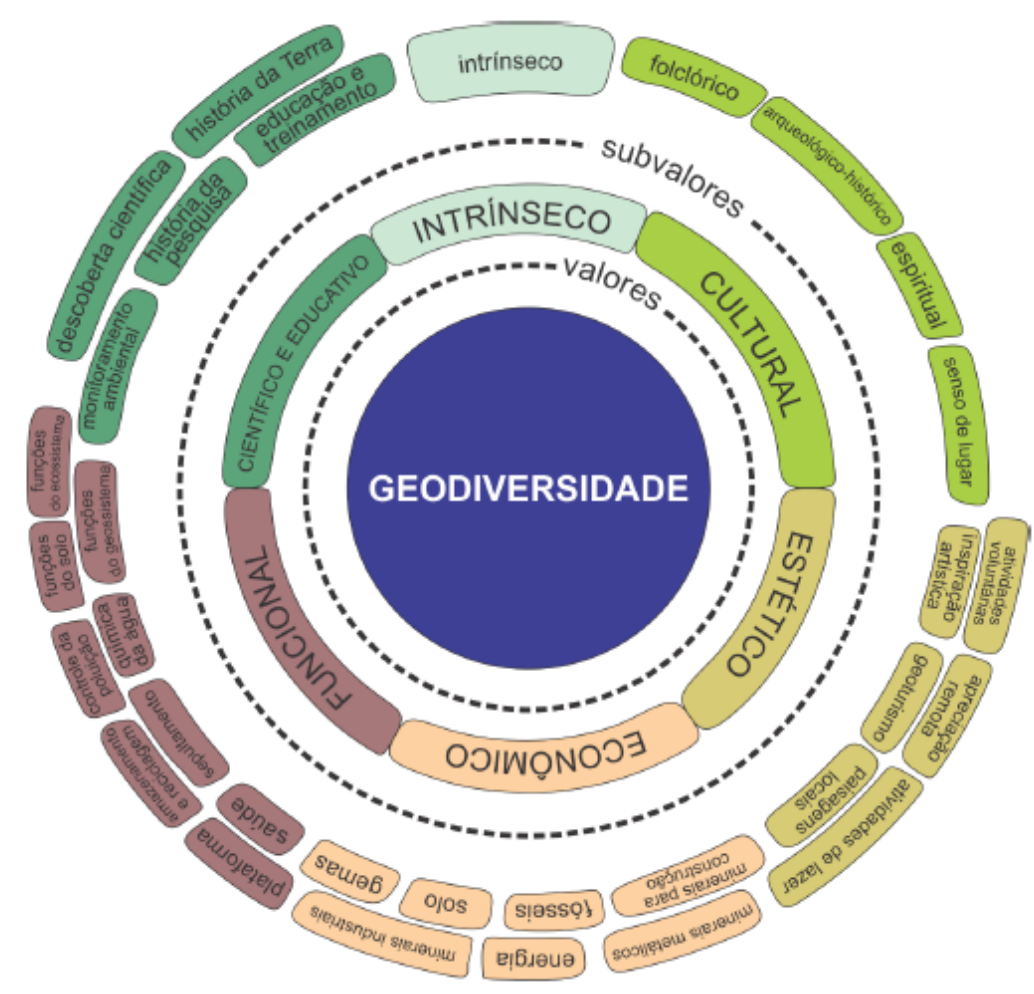

Figura 01: Diagrama simplificado do sistema de valores da Geodiversidade segundo Murray Gray, em 2004. Fonte: Silva (2016).

Porém, o que em 2004 Gray denominou de "Valores da Geodiversidade", ou seja, a importância destes recursos para o ser humano; devido a algumas questões de amadurecimento da temática e de maior facilidade de divulgação, em 2011 foi chamado pelo mesmo autor de "Serviços Geossistêmicos" e em 2013 redefinido por Gray, Gordon e Brown (2013) para "Serviços abióticos do ecossistema".

Esta última classificação, foi pautada na Avaliação Ecossistêmica do Milênio (MEA, 2005), que em seu primeiro capítulo resume a preocupação dos serviços ecossistêmicos como "entender o valor da natureza para os seres humanos". Desde então, surgiram várias propostas de classificação para os serviços ecossistêmicos (MEA, 2005; TEEB, 2008; CICES, 2010) que em sua maioria englobam quatro grandes grupos de serviços, que são: suporte, regulação, provisão e cultural.

Mas, a ênfase dada nestas classificações é aos serviços ecológicos prestados pela biodiversidade. Porém alguns estudos tentam, mesmo que de forma pontual, indicar algumas contribuições prestadas pelos elementos abióticos ao ecossistema, como o de Sousa et al, (2016) que se propõe a classificar os serviços ecossistêmicos prestados por uma região costeira complexa, localizada entre Porto e Lisboa em Portugal, chama Ria de Aveiro. Ou por Silva (2016) e Silva e 
Nascimento (2016) propondo a classificação dos serviços ecossistêmicos ligados a geodiversidade no litoral da cidade do Natal/RN no Brasil.

A classificação e mapeamento dos serviços na pesquisa de Sousa et al (2016), é feita por meio da Tabela CICES, que organiza suas classes em categorias, seções, divisões e grupos e que segundo Sousa et al., (2016) "considera as saídas dos ecossistemas dependentes do processo de vida", fazendo algumas contribuições ou classificações do ponto de vista abiótico de forma separada. Neste estudo de caso, por exemplo, associados aos serviços prestados pela parte ecológica da área, algumas considerações referentes as saídas abióticas, como: o fornecimento de substâncias minerais nutritivas (sal marinho) e a transição de materiais não-metálicos (areias e cascalho) associados a água costeira.

Estes são exemplos onde se tentou fazer uma associação preliminar de elementos da biodiversidade e Geodiversidade,. Porém, esta realidade ainda não é maioria e por conta disto, alguns pesquisadores como Gray, Gordon e Brown (2013) empenharam-se em mostrar como o meio abiótico também presta seus serviços para o ecossistema. Algumas destas contribuições podem ser vistas na figura 02 , abaixo:

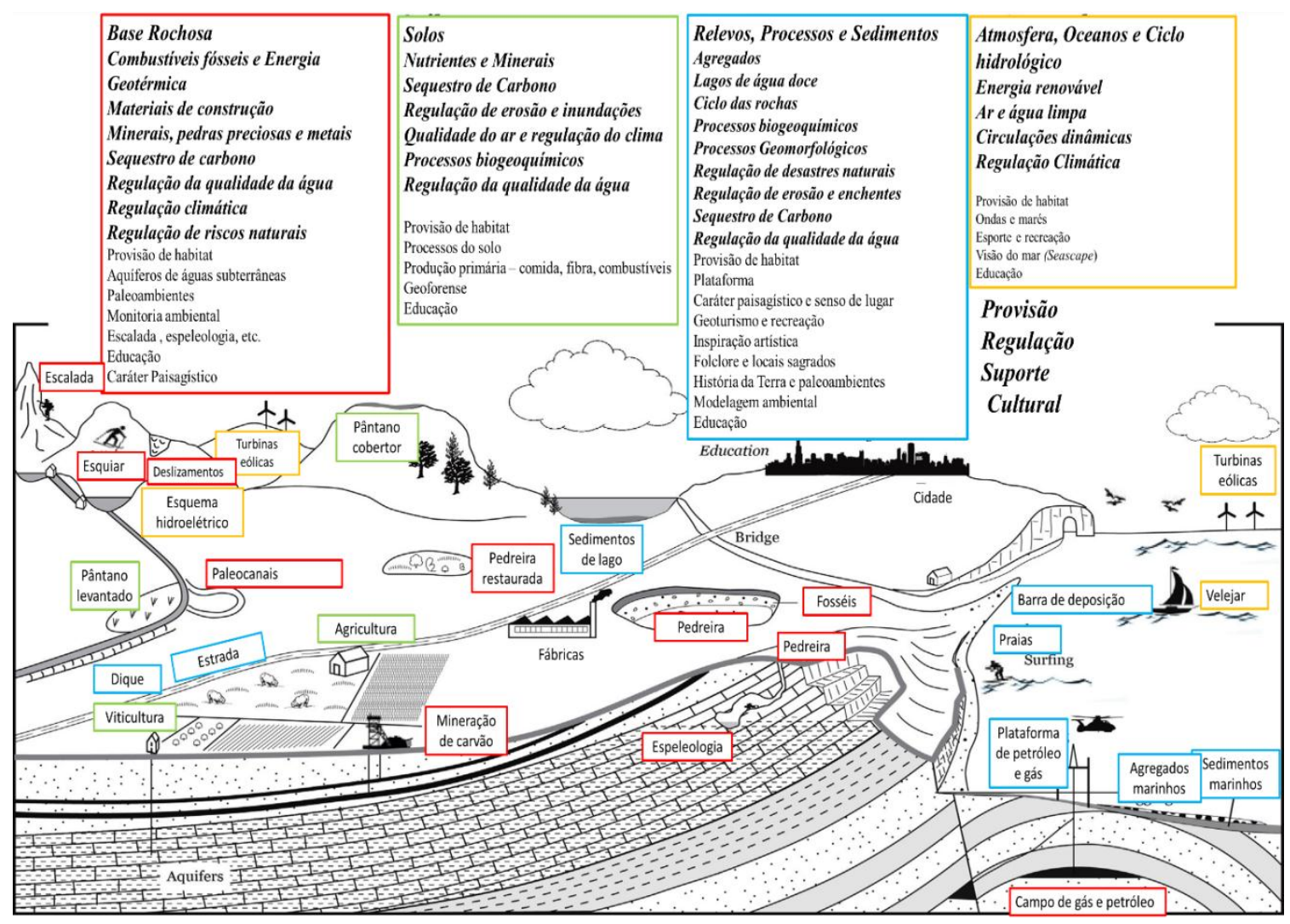

Figura 02: Bens e serviços prestados pela Geodiversidade segundo Gray, Gordon e Brown (2013). Fonte: Adaptado por Thiara Oliveira Rabelo, 2017. 
A figura 2, ajuda a compreender melhor como a Geodiversidade está presente em nossas vidas, visto que em muitas vezes não percebemos os muitos âmbitos que os elementos abióticos estão prestando serviços ao ser humano e ao ecossistema. Como exemplo disto, citamos o ecossistema manguezal, onde os serviços da biodiversidade são mais enfatizados.

Estes ambientes são entendidos geologicamente como depósitos flúvio-marinhos e segundo Maragon (2008) são constituídos por areias finas, siltes e argilas cuja a laminação é fina e que se depositam incorporando matéria orgânica, dando origem às argilas orgânicas marinhas. Esses sedimentos podem, por exemplo, influenciar na distribuição espacial das tocas de caranguejos, animais típicos destes ecossistemas, como foi indicado pelas pesquisas de Menezes (2007), que enfatiza características como temperatura, salinidade, natureza dos sedimentos e conteúdo dos substratos como importantes para o habitat destes animais.

Foi por conta de perceber relações como estas e observar que a Geodiversidade aparece em segundo plano em algumas análises e em outras por vezes nem mencionada no que se refere aos serviços ecossistêmicos é que Gray, Gordon e Brown (2013) apresentam quais seriam os "Serviços abióticos do ecossistema" divididos entre os serviços de suporte, de provisão, de regulação e cultural, sendo que os serviços de conhecimento encontram-se abarcados dentro da classe de serviço cultural.

A partir desta sistematização dos serviços ecossistêmicos prestados pelos elementos abióticos (Figura 03) fica mais fácil a compreensão sobre quais as formas que a Geodiversidade está direta e indiretamente envolvida com os ecossistemas. 


\section{GEODIVERSIDADE}

SERVIÇOS ABIÓTICOS PRESTADOS AOS ECOSSISTEMAS

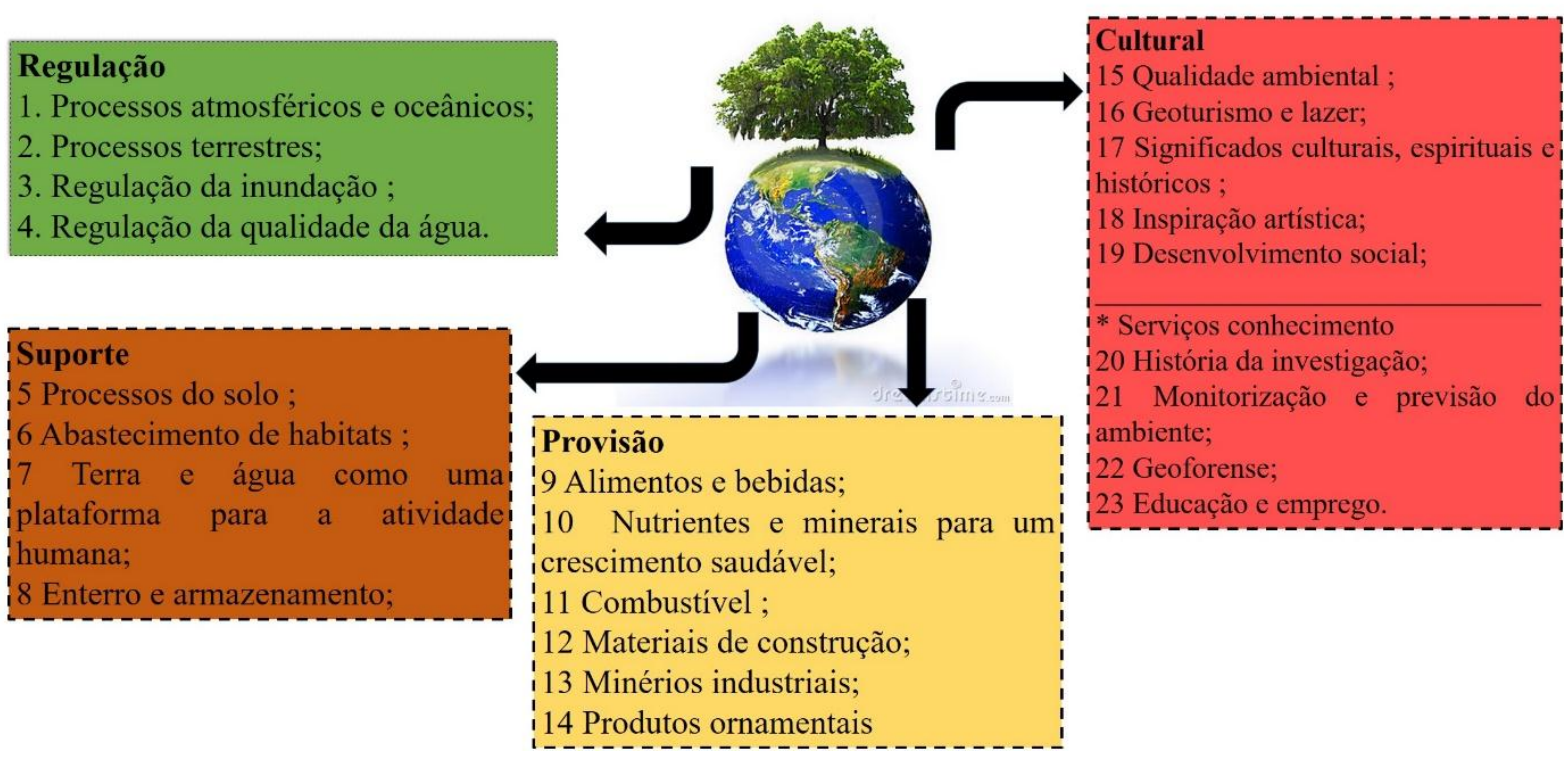

Figura 03: Serviços abióticos, dividido em 4 grandes grupos, prestados pelo ecossistema, propostos por Gray, Gordon e Brown (2013). Fonte: Elaborado pelos autores.

Os processos de regulação podem estar relacionados a dinâmicas químicas da atmosfera, qualidade do ar, regulação climática e etc. Já os serviços de provisão estão diretamente relacionados a alimentos e bebidas, como por exemplo a água doce e água mineral, nutrientes e minerais que contribuem para o crescimento de plantas, materiais de construção (tijolos, agregados, aço, cimento, betume, etc.).

No que se refere aos serviços de regulação podemos citar como exemplo o intemperismo do solo, desenvolvimento do perfil do solo, o solo como meio de cultura, habitats dinâmicos como pavimentos de calcário e cavernas, reservatórios de petróleo e gás e etc. Quanto aos serviços culturais fornecidos pela Geodiversidade destacamos a contribuição nas paisagens locais que podem ser terapêuticas para a saúde e o bem estar, atividades recreativas, coletas de fósseis, dentre outros.

Entender estes serviços também torna mais fácil a compreensão sobre os possíveis riscos e ameaças a Geodiversidade, sejam elas de cunho natural ou por meio de interferências antrópicas. Compreender estas ameaças faz com que seja pensada e planejada de forma mais eficaz medidas de proteção a estes recursos em consonância com os elementos bióticos, como por exemplo, em áreas de manguezais, que já são instituídas legalmente como áreas de preservação permanente e ainda assim são negligenciadas, podendo ser observados diversos impactos de cunho entrópico que afetam de forma negativa sua dinâmica natural. 


\subsection{A influência da Geodiversidade em áreas de manguezais}

Constanza et al., (1997) e Mukherjee et al., (2014) destacam como alguns dos principais Serviços Ecossistêmicos prestados pelo manguezal, os de: pesca, proteção costeira, proteção contra sedimentação, produção de madeira, indicador de risco ambiental, armazenamento de carbono, valor estético, alimento, ecoturismo e recreação, redução da poluição, produção de mel, bioremediação através da água, recursos energéticos, forragem e produtos farmacêuticos.

Levando em consideração que os bens produzidos pelo manguezal para sociedade são resultantes da combinação de processos envolvendo elementos bióticos e abióticos, tem-se um cenário em que fica evidente a relação de dependência da Geodiversidade para a prestação dos serviços deste ecossistema, destacando-se principalmente a contribuição da geologia, geomorfologia, clima e de fatores oceanográficos.

Em áreas de manguezais, destaca-se a importância de relacionar a contribuição da geodiversidade para o oferecimento destes serviços (Figura 04), visto que fatores como geologia, relevo, salinidades, condições climáticas, dinâmica de ondas e marés são fundamentais para a estrutura deste ecossistema, podendo contribuir a fixação de espécies florísticas distintas e para o abrigo de certas espécies da fauna (LACERDA, 2001).

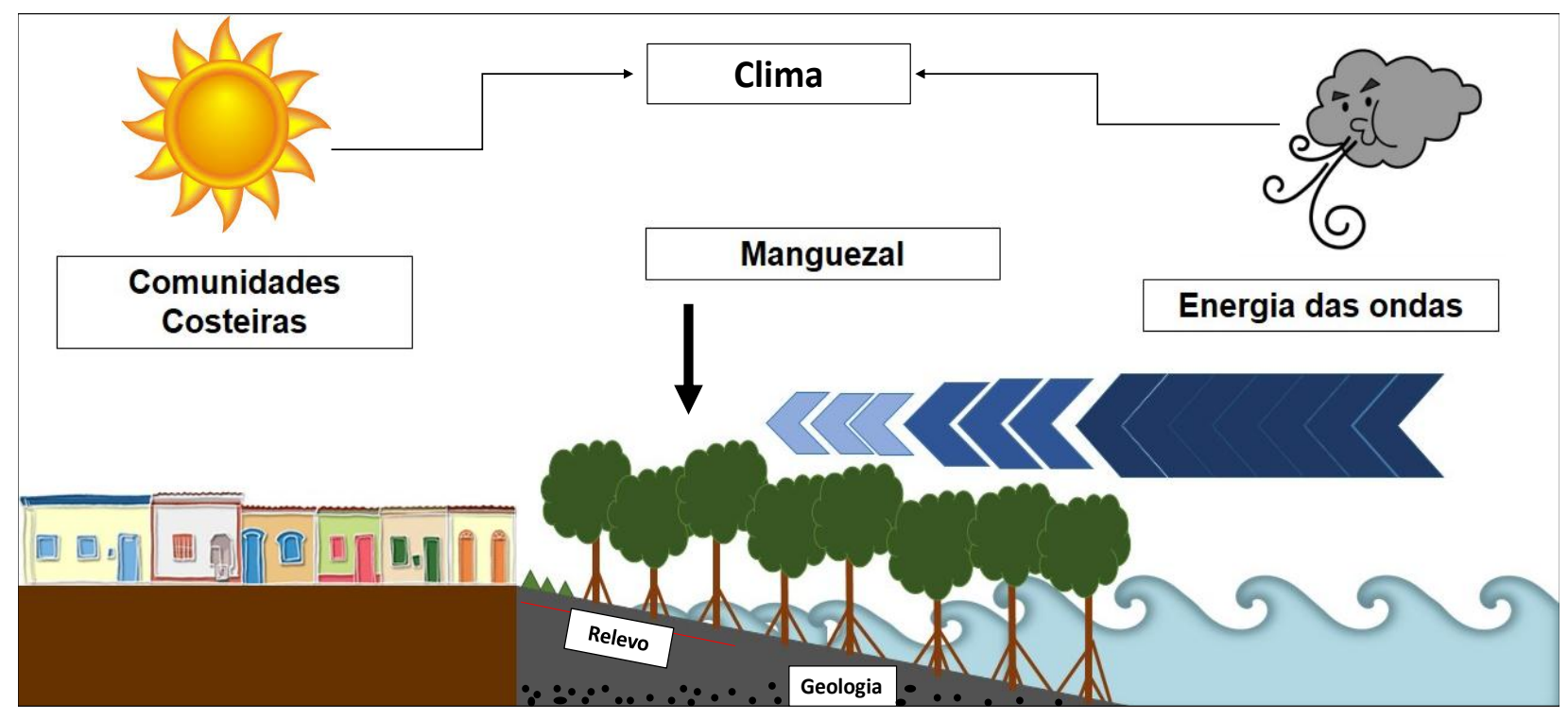

Figura 04: Esquema representativo dos fatores abióticos presentes em áreas de manguezais. Fonte: Adaptado de Nayara Marques Santos, (2017).

Quanto a geologia, o ecossistema manguezal, é compreendido como depósitos flúviomarinhos, sendo constituídos por areias finas, siltes e argilas, cuja laminação é fina e ocorrendo a 
incorporação da matéria orgânica, dando origem às argilas orgânicas marinhas (MARAGON, 2008). Esses sedimentos podem influenciar, por exemplo, a distribuição espacial das tocas de caranguejos, animais típicos destes ecossistemas, como foi indicado nas pesquisas de Menezes (2007). Este autor enfatiza ainda características como temperatura, salinidade, características dos sedimentos e conteúdo dos substratos, como importantes para o habitat destes animais (Quadro 1).

Em pesquisas realizadas no México, Mouton e Felder (1996) concluíram que a distribuição espacial dos caranguejos do gênero $U c a$ está altamente relacionada com as características do sedimento. Corroborando esta hipótese, e, estudos realizados em áreas de manguezais no norte do Brasil por Kock, Wolff e Diele (2005), estes autores afirmam que a morfologia dos apêndices alimentares destas espécies está adaptada ao manuseio do substrato, variando entre as espécies de acordo com a quantidade de material orgânico no substrato em que vivem.

Paixão et al., (2007) afirmam que os sedimentos do substrato do mangue e a pluviosidade exercem influência da dispersão e ocorrência das espécies de caranguejos, especialmente do gênero Uca spp. (Crustacea: Ocypodidae) no manguezal do Araçagy, na Ilha do Maranhão. Estes exemplos ajudam a destacar como elementos da geodiversidade (ex. sedimentos, minerais, solos e substratos) podem influenciar nos processos e serviços ecossistêmicos prestados pelo manguezal (SANTOS; SOUZA, 2016).

No que se refere aos fatores oceanográficos, a oscilação da maré e a energia das ondas são importantes fatores controladores na ocorrência e manutenção deste ecossistema (Quadro 1). O regime de marés é importante para a entrada da água salgada, nivelamento do solo e do teor de sal, transporte de sedimentos e nutrientes nos ambientes onde eles ocorrem (ex. estuários, baías, etc.). Quanto as ondas, o manguezal se desenvolve melhor em áreas com baixa energia de ondas, pois ondas fortes retiram as plântulas estabelecidas e os sedimentos (LUGO; SNEDAKER, 1974; TOMLINSON, 1986).

Mochel et al., (2001) e Nogueira e Correia (2001) enfatizam os poucos estudos referentes a algas na Ilha do Maranhão, tendo estes autores a preocupação de começar identificar estes organismos fotossintetizantes na área. Visto que os manguezais servem como substrato específico e satisfatório para as macroalgas e micro algas bênticas (PAULA, UGADIM e KANAGAWA, 1989), considerando as variações de salinidade da água.

É importante destacar que o manguezal se desenvolve em áreas planas, mais especificamente de planícies flúvio-marinhas (Figura 05), que geomorfologicamente são áreas de baixa cota altimétrica em relação ao nível médio do mar $(<1 \mathrm{~m})$, contribuindo principalmente para 
dissolução da água salgada em contato com a doce, combinação química homogênea necessária a ocorrências destes ambientes (MIRANDA et al., 2002). O clima é um dos elementos que exerce influência sobre o aporte fluvial, aporte de nutrientes e os gradientes de salinidade. Esses aspectos são regulados, pela temperatura, pluviosidade, evapotranspiração que variam de acordo com as características climáticas.

Figura 05: Linha amarela representando a variação do microrelevo da planície fluviomarinha do manguezal do rio Tijupá na Ilha do Maranhão, Estado do Maranhão. Fonte: Nayara Marques (2017).

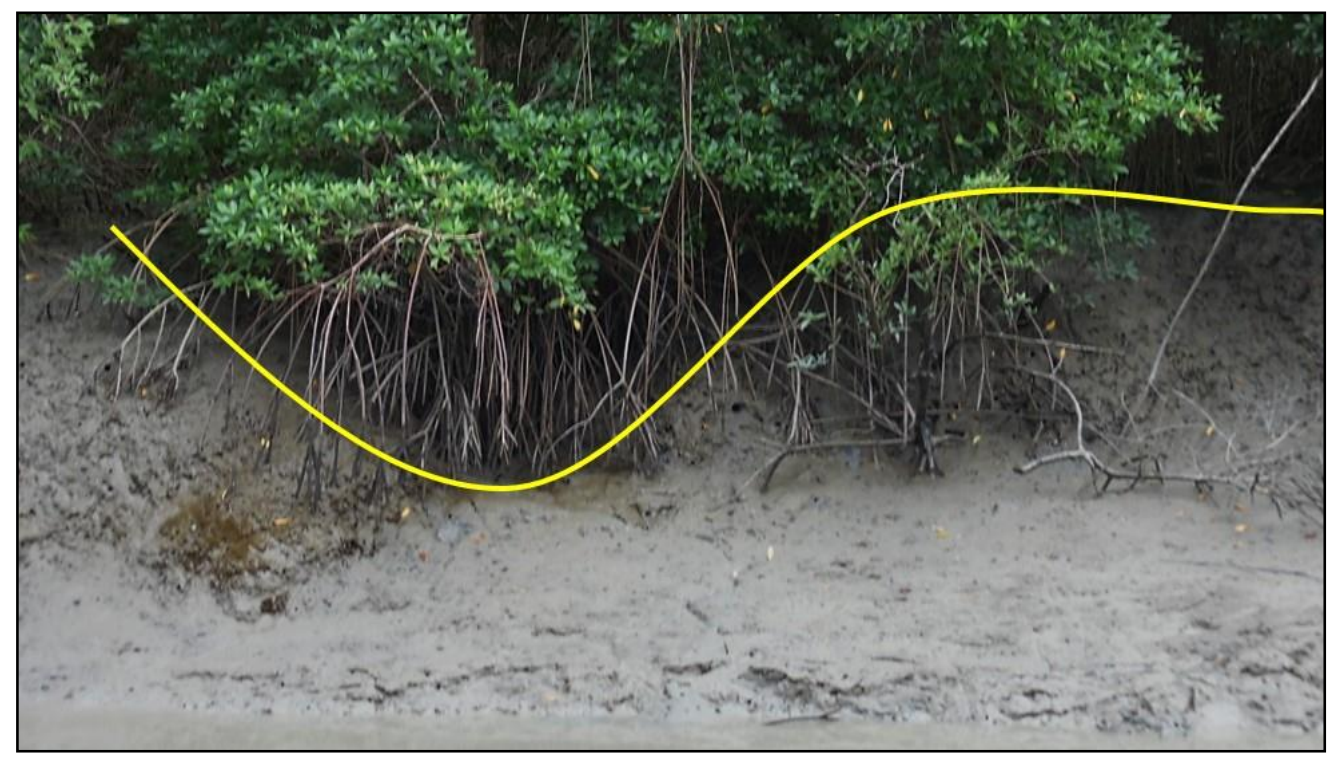

A partir do levantamento bibliográfico feito para esta pesquisa e de observações em atividades de campo feitos pelos manguezais do nordeste brasileiro, principalmente no Estado do Maranhão, foi possível elaborar um quadro-síntese representando os principais fatores de influência da Geodiversidade sobre o ecossistema manguezal (Quadro 01).

Quadro 01: Relação entre os elementos da Geodiversidade e os serviços ecossistêmicos prestados pelo manguezal. Fonte: Elaborada pelos autores.

\begin{tabular}{c|c|c|c|}
\hline $\begin{array}{c}\text { ELEMENTOS DA } \\
\text { GEODIVERSIDADE }\end{array}$ & FATORES & $\begin{array}{c}\text { INFLUENCIA NO } \\
\text { MANGUEZAL }\end{array}$ & $\begin{array}{c}\text { SER VIÇOS } \\
\text { INFLUENCIADOS }\end{array}$ \\
\hline \multirow{2}{*}{ CLIMA } & Temperatura & $\begin{array}{l}\text { - Condicionam a diversidade } \\
\text { e ocorrência da flora e fauna. }\end{array}$ & $\begin{array}{l}\text { Pesca, coleta de } \\
\text { caranguejo e mariscos, } \\
\text { extração de madeira; } \\
\text { regulação climática. }\end{array}$ \\
\hline & Pluviosidade & &
\end{tabular}




\begin{tabular}{|c|c|c|c|}
\hline GEOLOGIA & Sedimentos & $\begin{array}{l}\text { - Devido a sua estrutura, } \\
\text { favorecem: os processos } \\
\text { biológicos e geoquímicos; a } \\
\text { sedimentação para formação } \\
\text { do substrato; incorporação da } \\
\text { matéria orgânica; diversidade } \\
\text { de espécies de caranguejo. }\end{array}$ & $\begin{array}{l}\text { - Acumulo de carbono; } \\
\text { manter populações e } \\
\text { habitats de berçário; coleta } \\
\text { de caranguejo. }\end{array}$ \\
\hline RELEVO & Topografia & $\begin{array}{l}\text { - O relevo plano favorece a } \\
\text { diminuição da força das } \\
\text { águas, permitindo a } \\
\text { dissolução da água salgada; e } \\
\text { a deposição de sedimentos } \\
\text { finos (areia, silte e argila) } \\
\text { para formação das planícies } \\
\text { maré. }\end{array}$ & $\begin{array}{l}\text { - Estabilização e controle de } \\
\text { taxas de erosão; proteção da } \\
\text { linha de costa. }\end{array}$ \\
\hline \multirow{3}{*}{ OCEANOGRAFIA } & Ondas & $\begin{array}{l}\text { - A baixa energia de ondas } \\
\text { favorece o desenvolvimento } \\
\text { deste ecossistema. }\end{array}$ & $\begin{array}{l}\text { - Recuperação das áreas de } \\
\text { manguezal degradado } \\
\text { através da utilização de } \\
\text { propágulos. }\end{array}$ \\
\hline & Maré & $\begin{array}{l}\text { - Entrada de água salgada no } \\
\text { estuário; renovação da água e } \\
\text { do oxigênio; aporte de } \\
\text { nutrientes; manutenção dos } \\
\text { níveis de sal. }\end{array}$ & $\begin{array}{l}\text { - Pesca, diluição de } \\
\text { substâncias provenientes do } \\
\text { despejo de esgotos; criação } \\
\text { de mariscos. }\end{array}$ \\
\hline & Salinidade & $\begin{array}{lrr}\text { - Limita a ocorrência } & \text { das } \\
\text { glicófitas; necessário para } \\
\text { processos fisiológicos das } \\
\text { halófitas; quando r se } \\
\text { apresenta em altos níveis no } \\
\text { solo, limita } \\
\text { desenvolvimento estrutural } \\
\text { do manguezal. }\end{array}$ & $\begin{array}{l}\text { - Utilização das plantas do } \\
\text { mangue para alimentar } \\
\text { gado; os serviços de } \\
\text { provisão de pesca são } \\
\text { limitados pela menor } \\
\text { diversidade da fauna } \\
\text { (ambientes hipersalinos). }\end{array}$ \\
\hline HIDROLOGIA & Aporte fluvial & $\begin{array}{l}\text { - Dissolução da água salgada; } \\
\text { aporte de sedimento e } \\
\text { nutriente. }\end{array}$ & $\begin{array}{l}\text { - Diversidade de fauna e } \\
\text { flora do manguezal. }\end{array}$ \\
\hline
\end{tabular}

A partir das informações expostas no Quadro 01 e correlacionando com as discussões trazidas nas pesquisas acima mencionadas, como Mouton e Felder (1996), Lacerda, (2001), Paixão et al.(2007), Santos e Souza, 2016, dentre outros citados, é notório perceber que os elementos abióticos contribuem diretamente para prestação de serviços ecossistêmicos prestados por áreas de manguezais.

Sejam eles os serviços de provisão, onde a distribuição de sedimentos no substrato do mangue e a pluviosidade, podem ser fatores que influenciam na abundância e nos tipos de espécies 
deste ecossistema, por exemplo; ou os serviços de regulação onde, podemos citar como exemplo, o relevo plano favorece a diminuição da força das águas, sejam de origem marinha ou fluvial, estabilizando as taxas de erosão e manutenção da vegetação deste ecossistema. Ou ainda, na prestação dos serviços ecossistêmicos culturais onde a lama, o sal, a maré (elementos abióticos presentes nos manguezais) fazem parte, juntamente com os outros elementos do mangue, de poesias e cantigas criadas inspiradas neste ecossistema.

\section{CONSIDERAÇÕES FINAIS}

Ainda são incipientes os trabalhos que abordam a correlação das temáticas de Serviços Ecossistêmicos e Geodiversidade. Porém muitas pesquisas já fazem menção a contribuição dos elementos abióticos nestes ecossistemas e consequentemente aos serviços que podem ser prestados, mesmo sem fazer uso das denominações Serviços Ecossistêmicos e Geodiversidade.

A sistematização destas informações é primordial para estudos de áreas de manguezais de forma mais holística e para compreender a prestação de seus serviços para o ambiente, incluindo o homem e as outras formas de vida terrestre que estão associadas direta e indiretamente a estes ambientes. Relacionar os aspectos abióticos em um ecossistema onde a biodiversidade se destaca de forma mais intensa, é essencial para pensarmos a gestão de áreas de manguezais de forma mais completa, posto que a Geodiversidade mesmo não sendo o fator que visualmente mais se destaca nestes ambientes, desempenha papel importante para estes ecossistemas.

O manguezal tem seu funcionamento fortemente associado aos elementos abióticos, a combinação com a biota é responsável por diversos processos geoquímicos, portanto a presença dos elementos da Geodiversidade é essencial na produção dos Serviços Ecossistêmicos. Compreender a relevância das características abióticas na produção dos Serviços Ecossistêmicos é necessária para conhecer os fatores que potencializam ou limitam a diversidade e oferta dos serviços, assim como os diferentes usos pela sociedade. A discussão dos serviços abióticos da Geodiversidade é uma temática que necessita ser trabalhada sob ótica da abordagem sistêmica, considerando o contexto ambiental, social e econômico, e desta forma possa subsidiar o uso sustentável dos recursos naturais pela sociedade.

O quadro apresentado neste trabalho foi organizado de acordo com as características mais evidentes do ecossistema manguezal, sendo passíveis de alterações para estudos que envolva a identificação destes serviços abióticos para outros ecossistemas. Estudos posteriores que estejam 
dispostos a identificar novas contribuições relacionadas a regulação, etapas e processos do ecossistema manguezal e detalhar ainda mais as que aqui já forem identificadas são de fundamental importância, visto que os serviços ecossistêmicos estão intimamente ligados aos processos biológicos, físico-químicos do ambiente. Assim como possuem ligação direta com Geodiversidade da área, visto que os recursos abióticos se mostram diretamente relacionados como suporte para prestação destes serviços.

\section{REFERÊNCIAS}

BRILHA, J.B.R. Património geológico, geoconservação: A conservação da natureza na sua vertente geológica. Braga, Portugal: Palimage, 2005

COSTANZA, R.; D'ARGE, R.; FARBER, S.; GRASSO, M.; HANNON, B.; LIMBURG, K.; The value of the world's ecosystem services and natural capital. Nature, v. 1, p. 3-15, 1997.

DAILY, G. Nature's sercices: societal dependence on natural ecosystem. Washington: Island Press, $1997,350 \mathrm{p}$.

DE GROOT, R.S., WILSON, M.A.. BOUMANS, R.M.J. A typology for the classification, description, and valuation of ecosystem functions, goods and services. Ecological Economics 41.2002. p. 393-408

EUROPEAN COMMUNITIES. The Economics of Ecosystems and Biodiversty (TEEB). Interim report European Communities.68p. 2008. Disponível em: http://ec.europa.eu/environment/nature/biodiversity/economics/pdf/teeb_report.pdf.

GRAY, M. Geodiversity: valuing and conserving abiotic nature. Londres: John Wiley \& Sons Ltd., 2004. 434p.

GRAY, M. Other nature: geodiversity and geosystem services. Enviromental Conservations. p 271-274. 2011

GRAY, M.; GORDON, J.E.; BROWN, E. J. Geodiversity and the ecosystem approach: the contribution of geoscience in delivering integrated environmental management. Proceedings of the Geologists' Association, v. 124, 2013, p. 659-673.

HAINES-YOUNG, Roy; POTSCHIN, Marion. Common International Classification of Ecosystem Services (CICES): Consultation on Version 4, August-December. EEA - Framework Contract, n. EEA/IEA/09/003. Nottingham: University of Nottingham/Centre for Environmental Management, 2013. 
HJORT, J. et al. Why geodiversity matters in valuing nature's stage. Conservation Biology: the journal of the society for Conservation Biology. 2015. p. 630- 639.

JUNK, W. J. et al. Brazilian wetlands: their definition, delineation, and classification for research, sustainable management, and protection. Aquatic Conserv: Mar. Freshw. Ecosyst., v. 24, p. 5-22, 2014.

KOCH, M.; MATTHIAS, W. e DIELE, K. Comparative population dynamics of four fiddler crabs (Ocypodidae, genus Uca) from a North Brazilian. Marine Ecology Progress Series. Vol. 291: 177-188, Abril, 2005. Disponível em: http://www.intres.com/articles/meps2005/291/m291p177.pdf..

LACERDA LD. Mangrove Ecosystems: Function and Management. Springer Verlag: Berlin. 2001.

LIMBURG, K. E.; FOLKE, C. The ecology of ecosystem services: introduction to the special issue. Ecological Economics, v. 29, p. 215-233. 1999.

LUGO, A. E.; SNEDAKER, S. C. The ecology of mangroves. Annual Review of Ecology and Systematics, v. 5, 1914, p. 39-64.

MARAGON, M. Geotecnia de Fundações. Formação Geológica dos Solos. Nugeo. Universidade Federal do Rio de Janeiro. 2008. Disponível em : http://www.ufjf.br/nugeo/files/2009/11/GF111Formacao-Geologica-dos-Solos-2008.pdf.

MENEZES, C. O Substrato influencia a distribuição espacial de tocas de caranguejos ChamaMaré Uca sp. (Decapoda, Ocypodidae)? Ecologia da Mata Atlântica. 2007. Disponível em: http://ecologia.ib.usp.br/curso/2007/pdf/individuais/i_cristiano_menezes.pdf.

MIRANDA, L.B.; CASTRO, B.M.; KJERFVE, B. Princípios de oceanografia física de estuários. São Paulo: Editora da Universidade de São Paulo, 2002, 424 p.

MOUTON, E.C.; FELDER, D.L.. Burrow distributions and population estimates for the fiddler crabs Uca spinicarpa and Uca longisignalis in a Gulf of Mexico salt marsh. Estuaries, v. 18, n. 3, 1995, p. 469-481.

MILLENNIUM ECOSYSTEM ASSESSMENT (MEA). Ecosystem and Human Well-Being: A framework for assessment. Washington, D.C.: Island Press. 2003. Disponível em: http://pdf.wri.org/ecosystems_human_wellbeing.pdf.

MOCHEL, F.R. et al. Degradação dos Manguezais na Ilha de São Luís (MA): processos naturais e impactos antrópicos. In: Prost, M.T.R.C e Mendes, A. Ecossistemas Costeiros: Impactos e Gestão Ambiental. Belém: Museu Paraense Emílio Goeldi, 2001. 
MUKHERJEE, N. et al. Ecosystem service valuations of mangrove ecosystems to inform decision making and future valuation exercises . Plos One, v. 9, n. 9.: e107706. 2014. Disponível em: http://journals.plos.org/plosone/article?id=10.1371/journal.pone.0107706.

NASCIMENTO, M.A.L. do et al. Geodiversidade, Geoconservação e Geoturismo: trinômio importante para a conservação do patrimônio geológico. UFRN/Biblioteca Central Zila Mamede. 2008.

NOGUEIRA, N. M. C. e FERREIRA-CORREIA, M. M. Cyanophyceae/cyanobacteria in red mangrove forest at mosquitos and coqueiros estuaries, São Luís, state of Maranhão, Brazil. Braz. J. Biol. vol.61 no.3 São Carlos Aug. 2001. 10 p. Disponível em: http://www.scielo.br/scielo.php?script=sci_arttext\&pid=S1519-69842001000300002. Acesso: $16 / 10 / 2016$.

PAIXÃO, V.M. et al. Ocorrência e abundância de caranguejos chama-marés do gênero Uca (crustacea, ocypodidae) no manguezal do araçagy, Ilha São Luís, Maranhão. In: VIII Congresso de Ecologia do Brasil. Anais. Caxambu - MG, 23 a 28 de Setembro de 2007,. 2 pg. Disponível em: http://www.seb-ecologia.org.br/viiiceb/pdf/803.pdf.

PAULA, E. J. de.; UGADIM, Y. e KANAGAWA, A. I. Macroalgas de manguezais da Ilha de Maracá - Estado do Amapá, Brasil. Revista Insúla. Florianópolis. nº 19. 1989. P 94-114.

SANTOS, G.C. dos. E SOUZA, R. M. Manguezais do litoral sul centro e sul de Sergipe: vulnerabilidade e perda da vegetação associada aos tensores naturais e antropogênicos. In: SOUZA, R. M. et al. Riscos e Vulnerabilidades da Gestão Territorial. Aracaju: Criação editora. 2016. 149-167. p. Disponível em: http://www.geoplan.net.br/Livro_Geoplan_III_Ciclo_de_Palestras.pdf.

SOUZA, L.P.; SOUZA, A.I.; ALVES, F.; LILLEBO, A.I. Ecossystem Services provided by a complex costal region: challenges of clasification and mapping. Scientific Reports, $v$ 6, n. 22782, 2016.

SILVA, M. L. N. da. Geodiversidade na cidade de Natal (RN): valores, classificações e ameaças. Relatório de Graduação apresentado ao curso de Geologia da Universidade Federal do Rio Grande do Norte. Natal: UFRN. 2016.

SILVA, M.L. N.da. e NASCIMENTO, M.A.L. do. Os valores da Geodiversidade de acordo com os Serviços Ecossistêmicos Sensu Murray Gray aplicados a estudos in situ na cidade de Natal (RN). Caderno de Geografia. V. 26. Número Especial 2. 2016.

SCOTT, D.A.; JONES, T. A. Classification and inventory of wetlands: a global overview. Vegetatio, v. 118, n. 3, p.16, 1995 
SILVA, J. de P. Avaliação da Diversidade de padrões de canais fluviais e da geodiversidade na amazônia - aplicação e discussão na bacia hidrográfica do Rio Xingu. Tese apresentada ao Departamento de Geociências da USP. São Paulo. 2012.

TOMLINSON, P. B. The botany of mangroves. Cambridge-UK, Cambridge University Press,. 1986. 419p.

\section{AGRADECIMENTOS}

Somos gratos a Coordenação de Aperfeiçoamento de Pessoal do Nível Superior pela concessão da bolsa de mestrado através do Programa de Pós-graduação em Geografia da Universidade Federal do Rio Grande do Norte, que contribui para o andamento desta pesquisa.

Recebido em: 15/08/2018

Aceite para publicação em: 05/11/2018 